\title{
The effects of magnesium and aluminium ions' additions on the kinetics of titanium dioxide structural transformation
}

\author{
Maciej Jablonski • Magdalena Olszak-Humienik
}

Received: 2 October 2012/ Accepted: 28 December 2012/Published online: 10 February 2013

(C) The Author(s) 2013. This article is published with open access at Springerlink.com

\begin{abstract}
Knowledge of kinetics structural transformation of titanium dioxide is very important for the calcination process in titanium white production. Some impurities of titanium raw could have the influence in the crystalline structure of products and the kinetics of transitions. Sulphate salts of aluminium or magnesium were added into samples of $\mathrm{TiO}_{2}$ suspension. After drying, the samples were studied by thermogravimetry at a heating rate of $10 \mathrm{~K} \mathrm{~min}^{-1}$ to temperature at $1,000{ }^{\circ} \mathrm{C}$. Results of thermogravimetric investigations of dry titanium dioxide suspension show two-stage decreases of sample mass: the first stage is associated with the removal of water, and the second stage is related to the emission of sulphur oxides. A method of X-ray diffraction (XRD) was used in the investigation of the kinetics of anatase-rutile transformation. The samples after drying were heated at 750, 800, 850 or $900{ }^{\circ} \mathrm{C}$ in a muffle furnace for $70 \mathrm{~min}$, and then the phase composition was analysed using the XRD method. The results of XRD measurements show that at a temperature of $800{ }^{\circ} \mathrm{C}$ after $60 \mathrm{~min}$, the complete transformation of titanium dioxide into rutile occurs. The addition of $\mathrm{Al}$ ions to the suspension of $\mathrm{TiO}_{2}$ has a negative influence on (increases) the time it takes for the complete transformation of the anatase into rutile. Analysis of these phase-transformation diffractograms led to an activation energy in the Avrami-Erofeev model with $n=8 / 3$ of $178 \mathrm{~kJ} \mathrm{~mol}^{-1}$. The influence of the $\mathrm{Mg}$ ion's addition on the kinetics of the phase transformation is negligible.
\end{abstract}

M. Jablonski $(\varangle) \cdot$ M. Olszak-Humienik

Institute of Chemistry and Environmental Protection, West

Pomeranian University of Technology, Szczecin, Al. Piastów 42,

71-065 Szczecin, Poland

e-mail: jablom@zut.edu.pl
Keywords Kinetics - Phase transformation - Titanium dioxide $\cdot$ Additions of aluminium and magnesium

\section{Introduction}

The kinetics of the phase transformation of titanium dioxide has been studied because of its technological importance and theoretical interest. The main raw material for titanium dioxide production is ilmenite. Apart from elements like titanium and iron, other elements, such as magnesium and aluminium, are found in this raw material. In sulphate technology of titanium dioxide production, after a digestion, clarifying and hydrolysis processes, the calcination of titanium dioxide occurs. Successive processes and operations are unable to completely remove all accompanying elements.

In the process of white titanium pigments production using the sulphate method, titanium dioxide is obtained from titanium raw materials through the reaction with the sulphuric acid. Products of these reactions are used in the hydrolysis processes, and as a result of this reaction, hydrate titanium dioxide $\left(\mathrm{TiO}_{2} \cdot n \mathrm{H}_{2} \mathrm{O}\right)$ is obtained. In order to obtain titanium dioxide as rutile structure, the process of calcination of hydrate $\mathrm{TiO}_{2}$ at the temperature about $950{ }^{\circ} \mathrm{C}$ is employed. The presence of accompanying elements can exert influence on temperature as well as kinetics of the anatase-rutile transformation [1-9].

The investigation of $\mathrm{TiO}_{2}$ phase transformation has been the subject of many articles [10-20].

As a result of the digestion process, titanium compounds, as well as accompanying elements are transferred to the solution phase. Depending on the concentration, these elements can appear in intermediates during the process and can affect reagents' properties and the kinetics of individual processes. 
Small amounts of additives such as sodium, potassium, aluminium, magnesium, zinc ions, etc. are responsible for the changes of temperatures of transformations (anataserutile) and thus can exert their influence on the rate of this transformation. Also, these substances have the essential influence on the physicochemical properties of the rutile phase [2-9].

Knowledge about the kinetics of titanium dioxide transformation with aluminium and magnesium salts as additives, enables us to estimate the transition degree depending on the conditions of the industrial process.

Structural and phase transformations in solid are very slow and can be classified phenomenologically according to the order of the transition. The rate with which the system achieves an equilibrium state is the kinetic issue. In a solid state, the thermodynamic instability can lead to freezing.

Before beginning the kinetic study of anatase-rutile transformation, the thermodynamic function changes [21, 22] of this transition were analysed. From the results of this analysis, we observe that the transition is accompanied by an enthalpy change and the anatase is metastable phase.

\section{Experimental}

In the process of heating, the suspension of titanium dioxide, stages of dehydroxylation and emission of sulphur oxides occured. The influence of added salts to samples of $\mathrm{TiO}_{2}$ suspension for these processes was investigated using thermogravimetric method.

Thermogravimetric and derivative thermogravimetric investigations of the titanium dioxide suspension samples were realized on derivatograph MOM (Hungary) 1500C. Samples were prepared from a solution of titanium sulphate which, after hydrolysis, contained $29.8 \mathrm{wt} \% \mathrm{TiO}_{2}$, $2.7 \mathrm{wt} \% \mathrm{SO}_{3}$. The density of suspension was equal $1.277 \mathrm{~g} \mathrm{~cm}^{-3}$. On the basis of this solution, samples were prepared with the addition of 0.20 or $0.50 \mathrm{wt} \% \mathrm{Al}_{2}\left(\mathrm{SO}_{4}\right)_{3}$ and 0.18 or $0.45 \mathrm{wt} \% \mathrm{MgSO}_{4}$, respectively. Before the measurement the samples were dried at a temperature of $105^{\circ} \mathrm{C}$ to constant mass. The mass of the samples was $0.6 \mathrm{~g}$. The measurements were realized in a temperature range of $20-1,000{ }^{\circ} \mathrm{C}$ in air atmosphere at a heating rate of $10 \mathrm{~K} \mathrm{~min}^{-1}$. Aluminium or magnesium sulphates were added to some samples of $\mathrm{TiO}_{2}$ suspension in such an amount that after heating at $750{ }^{\circ} \mathrm{C}$ and higher, their concentrations in products were 0.2 and $0.5 \mathrm{wt} \% \mathrm{Al}_{2} \mathrm{O}_{3}$ and similarly for magnesium.

A method of the X-ray diffraction (XRD) was used in the investigation of the kinetics of phase transformation. The samples used in the investigations of the kinetics of the titanium dioxide phase transformation were prepared in a similar manner to that used in the thermogravimetry method. After drying, the samples were heating to temperatures of $750,800,850$ or $900{ }^{\circ} \mathrm{C}$ in a muffle furnace for the required time, and then after this, the phase composition was analysed by the XRD method.

The samples of titanium dioxide were cooled and then put into a diffractometer. Measurements were taken using a Philips PW1710 diffractometer, with a copper anode lamp $K_{\alpha 1}=1.54060$ and $K_{\alpha 2}=1.54438$, in an angle range two theta from $24^{\circ}$ to $29^{\circ}$, with current parameters $40 \mathrm{kV}$ and $35 \mathrm{~mA}$.

\section{Results}

The results of thermogravimetric investigations of samples of hydrated titanium dioxide with the additions of $\mathrm{Mg}$ and $\mathrm{Al}$ ions (and without these additions) are presented on Fig. 1. A two-stage decrease in the mass of the samples can be seen from the graph. The first stage is related with dehydroxylation of hydrated titanium dioxide which is occurring in the range of 100 to about $500{ }^{\circ} \mathrm{C}$. Experimental mass decrease of the samples without additions for the dehydroxylation process is about $13 \mathrm{wt} \%$, and for the next stage is about $9 \%$.

In the case of hydrated titanium dioxide samples with the additions of magnesium or aluminium, the shapes of thermogravimetric curves are similar to the curves of hydrated titanium dioxide transformations without additions, but mass losses are inconsiderably higher, and the same two-stages of mass decreases are visible.

The dehydroxylation and emission of sulphur oxides occurred in similar ranges of temperatures irrespective of the applied addition, which is exactly visible on Fig. 2. Figures. 1 and 2 show that the additions of $\mathrm{Mg}^{2+}$ or $\mathrm{Al}^{3+}$ ions to the suspension of $\mathrm{TiO}_{2}$ caused an increase in the amount of water removed in the first stage of

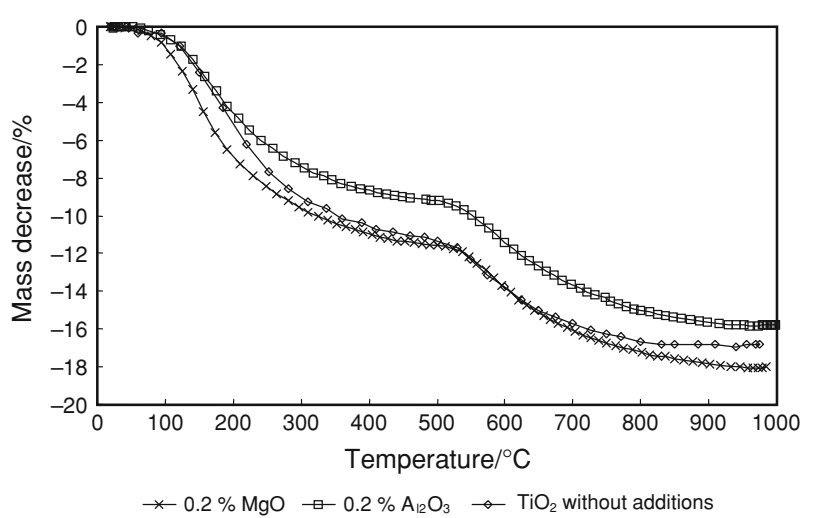

Fig. 1 Mass changes in the process of heating samples of hydrous titanium dioxide without and with additions 
decomposition. Fig. 2 shows that the maximum rate of mass losses in the dehydration process is higher in the case of samples with additions. The next stage of mass decrease related to emission of sulphur oxides is observed at the temperature of $500{ }^{\circ} \mathrm{C}$. The influence of additions on the process of emission of sulphur oxides is rather slight.

The influence of additions on temperatures of the phase transformation is small, and it is visible on the DTA curves (Fig. 3). This transformation occurs in the range of temperatures from about 750 to $850{ }^{\circ} \mathrm{C}$, and only a slight delaying effect in the case of addition of the aluminium is visible. Addition of $\mathrm{Al}$ ions shifted the maximum transformation temperature toward higher temperatures.

Results of XRD measurements are presented in the three-dimensional graph (Fig. 4) with a temperature of $800{ }^{\circ} \mathrm{C}$ for the transformation of titanium dioxide without additions. The first peak on the diffractogram (for the angle two Theta of $25.4^{\circ}$ ) indicates the presence of the anatase phase, and the second one (for the angle two Theta of $27.5^{\circ}$ ) the presence of the rutile phase. The values of extent of anatase-rutile transition $\alpha$ versus time $-t$ were estimated from the maximum of peak intensities in Fig. 4. The calculation of the mass fraction of rutile in the samples was based on the relationship [6, 17].

$\alpha_{\mathrm{r}}=I_{\mathrm{r}} /\left(k_{\mathrm{a}} I_{\mathrm{a}}+I_{\mathrm{r}}\right)$

where $I_{\mathrm{a}}$, and $I_{\mathrm{r}}$ are the intensities of anatase and rutile, respectively, and $k_{\mathrm{a}}$ is the calibration constant.

These mass fractions-time $\alpha-\tau$ dependences for all temperatures are depicted in Fig. 5. The slowest rate of transformation occurs at a temperature of $750{ }^{\circ} \mathrm{C}$, and after $70 \mathrm{~min}$, the transition degree is equal to 0.55 . The character of $\alpha$ (transition degree) versus $\tau$ (time) curve at $750{ }^{\circ} \mathrm{C}-$ "transition profile" accelerates, but the kinetic curve at this temperature span probably occurs in the induction period only.

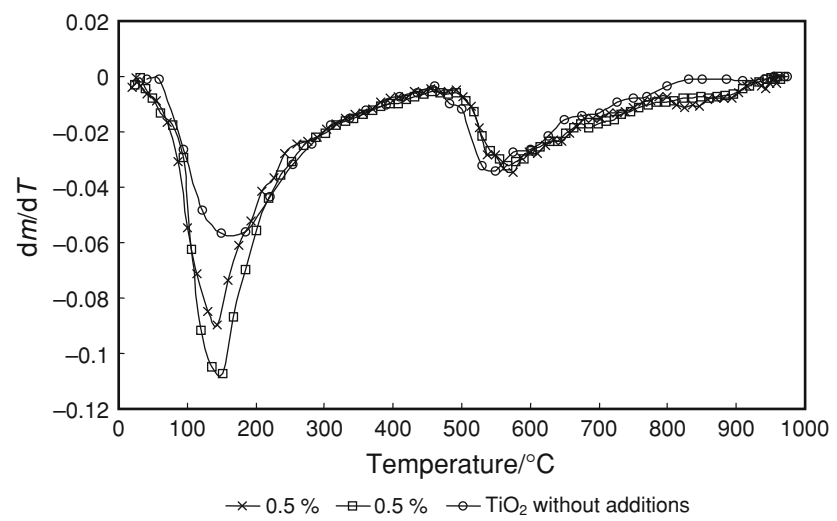

Fig. 2 The dependence of the derivative of sample mass with respect to temperature on the temperature and the applied addition

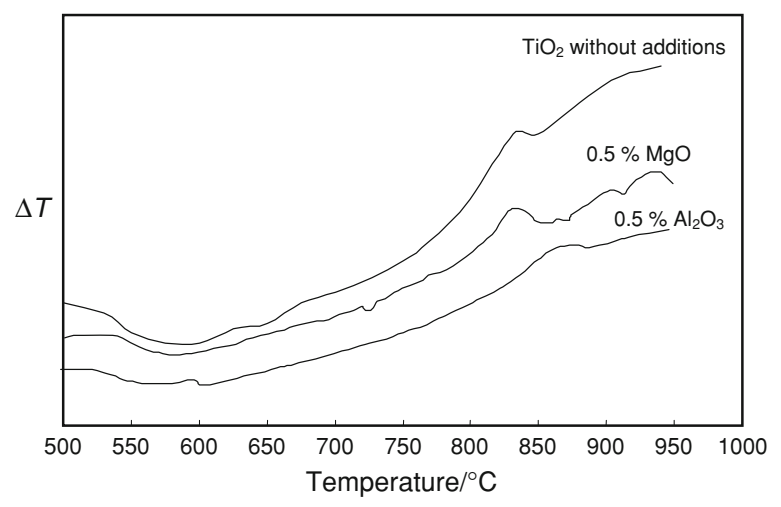

Fig. 3 DTA curve for $\mathrm{TiO}_{2}$ samples without and with additions

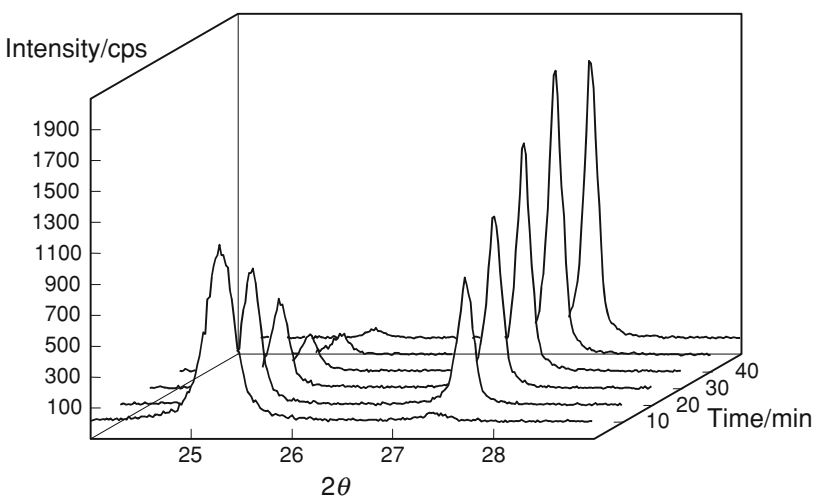

Fig. 4 Phase transformation of titanium dioxide without additions at temperature of $800{ }^{\circ} \mathrm{C}$

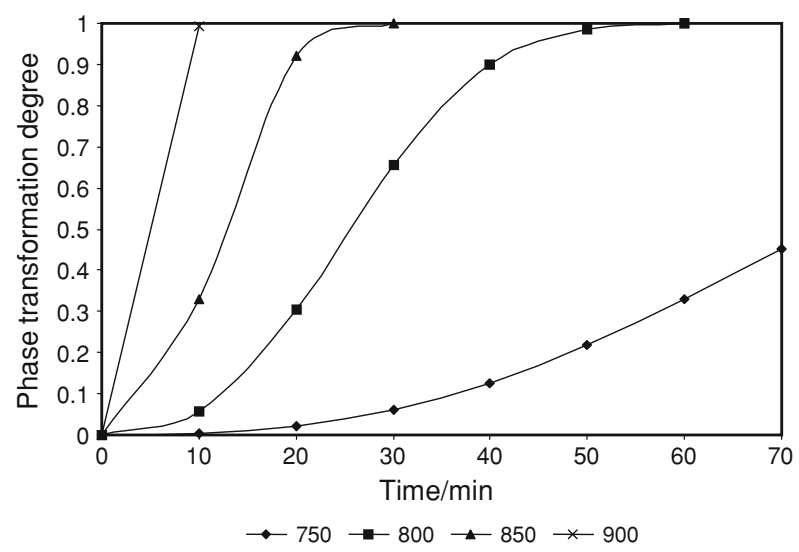

Fig. 5 Dependence of $\mathrm{TiO}_{2}$ without additions on transformation degree on time at different temperatures

It appears (Fig. 5) that at a temperature of $800{ }^{\circ} \mathrm{C}$ the character of the "kinetic curve" of phase transformation of titanium dioxide from anatase to rutile is different to that for $750{ }^{\circ} \mathrm{C}$, but similar to Avrami-Erofeev reaction models and the process is complete after $60 \mathrm{~min}$. The 'transition profile' of $\mathrm{TiO}_{2}$ transformation at this temperature is 
clearly sigmoidal. The phase transition process rate reaches its maximum at some intermediate value along the extent of transition.

A big difference in the rate of the transformation occurs between temperatures of 750 and $800{ }^{\circ} \mathrm{C}$, while the smallest difference occurs between temperatures of 850 and $900{ }^{\circ} \mathrm{C}$. A significant increase in the rate of the transformation is observed practically above temperatures of $800{ }^{\circ} \mathrm{C}$.

It can be seen from Fig. 5 that, at the temperature range of $850-900{ }^{\circ} \mathrm{C}$, the 'transformation profiles' of phase transition are of a decelerating character and reaches a transformation degree of equal to unity after $30 \mathrm{~min}$ at $850{ }^{\circ} \mathrm{C}$ and after $10 \mathrm{~min}$ at $900{ }^{\circ} \mathrm{C}$. The induction periods are less than $10 \mathrm{~min}$. The smallest difference among the progress of kinetic curves is observed between temperatures 850 and $900{ }^{\circ} \mathrm{C}$.

The kinetics of $\mathrm{TiO}_{2}$ structural transformation was described as being similar to the kinetics of the chemical reaction by the following equation:

$\frac{\mathrm{d} \alpha}{\mathrm{d} \tau}=k(T) f(\alpha)$

where $\tau$ is the time [min], $k(T)$ is the transformation rate constant at absolute temperature $T\left(\mathrm{~min}^{-1}\right)$, and $f(\alpha)$ is the transition function dependent on mechanism of the process.

$k(T)=A \exp \left(-\frac{E}{R T}\right)$

where $A$ is the pre-exponential Arrhenius factor $\left(\mathrm{min}^{-1}\right)$, and $E$ is the apparent energy of activation $\left(\mathrm{kJ} \mathrm{mol}^{-1}\right)$.

For isothermal experiments,

$\frac{\mathrm{d} \alpha}{f(\alpha)}=k \mathrm{~d} \tau$

and the integration of the above equation leads to

$g(\alpha)=\int_{0}^{\alpha} \frac{\mathrm{d} \alpha}{f(\alpha)}=k \tau$

From the $\alpha(\tau)$ dependences (Fig. 5) and well-known kinetic models [23-25], the $g(\alpha)$ functions which best described the isothermal experimental results of the phase transition were chosen.

For sigmoidal kinetics of processes, the following Avrami-Erofeev models of transformation are recommended:

$f(\alpha)=n(1-\alpha)[-\ln (1-\alpha)]^{\frac{n-1}{n}}$

and

$g(\alpha)=[-\ln (1-\alpha)]^{\frac{1}{n}}$

The experimental dependencies $g(\alpha)$ versus $\tau$ for different models were plotted, and using nonlinear regression method [26], the best model was chosen. The best result was found for Avrami-Erofeev model with $n=8 / 3$.

On the basis of the values of transition rate constant for particular temperatures of experiments, the dependence of ln $k$ versus $1 / T$ was plotted, and the equation describing the dependence was found:

$\ln k=\ln A-\frac{E}{R T}$

where $A=1.475 \times 10^{7} \mathrm{~min}^{-1} ; E=178.0 \mathrm{~kJ} \mathrm{~mol}^{-1} ; R$ is the molar gas constant equals $8.3145 \times 10^{-3} \mathrm{~kJ} \mathrm{~mol}^{-1} \mathrm{~K}^{-1}$. This energy of activation value is lower than reported by Shannon et al. [19] and Gennari et al. [1].

The rate of $\mathrm{TiO}_{2}$ anatase-rutile structural transformation can be described by the following equation:

$\frac{\mathrm{d} \alpha}{\mathrm{d} \tau}=\frac{8}{3} A(1-\alpha)[-\ln (1-\alpha)]^{5 / 8} \exp \left(-\frac{E}{R T}\right)$

The maximum of anatase-rutile transformation rate $(\mathrm{d} \alpha / \mathrm{d} \tau)_{\max }$ is observed for the transformation degree for which the derivative of function $f(\alpha)$ equals 0 . For $n=8 / 3$, the derivative of $f(\alpha)$ is as follows:

$$
\begin{gathered}
f^{\prime}(\alpha)=\frac{8 \ln (1-\alpha)+5}{3(-\ln (1-\alpha))^{3 / 8}} \\
f^{\prime}(\alpha)=0 \text { for } \alpha=0.4647 .
\end{gathered}
$$

Figures 6 and 7 show the influence additions of $\mathrm{Al}_{2} \mathrm{O}_{3}$ on the kinetics of the process of the phase transformation of titanium dioxide at temperatures of 800 and $850{ }^{\circ} \mathrm{C}$, respectively. Figures 6 and 7 show the delaying effects of the addition of $\mathrm{Al}_{2} \mathrm{O}_{3}$. Together with the increase of the $\mathrm{Al}_{2} \mathrm{O}_{3}$ concentration, the extension of duration of the anatase-rutile structural transformation is observed. Increasing the temperatures used in the process clearly affects the acceleration of the structural transformation. At both the temperatures, aluminium has a significant inhibitory influence on the phase transformation when an increase of the aluminium concentration is visible.

Addition of $\mathrm{MgO}$ (Fig. 8) is shown to have little influence on the kinetics of the anatase-rutile transformation. The transformations at the respective temperatures are similar to the processes of the sample without additions.

For samples where $\mathrm{Mg}$ or $\mathrm{Al}$ salts (Figs. 6, 7, 8) are added, the character of transition profiles after calcinations for transformation degree versus time is similar to the kinetic curves for samples without any addition. The extension of duration of complete anatase-rutile transformation is observed together with the increasing concentration of the $\mathrm{Al}_{2} \mathrm{O}_{3}$. 


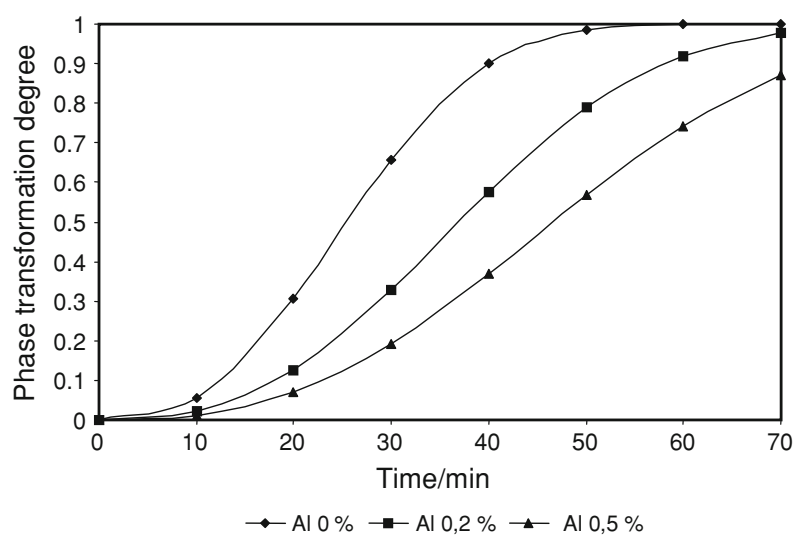

Fig. 6 Influence due to the addition of $\mathrm{Al}_{2} \mathrm{O}_{3}$ on the $\mathrm{TiO}_{2}$ transformation degree at temperature of $800{ }^{\circ} \mathrm{C}$

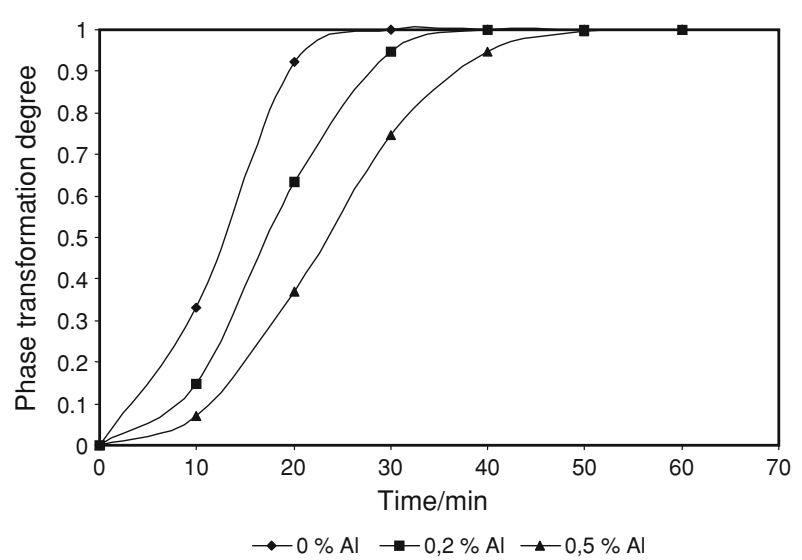

Fig. 7 Influence due to the addition of $\mathrm{Al}_{2} \mathrm{O}_{3}$ on the $\mathrm{TiO}_{2}$ transformation degree at temperature of $850{ }^{\circ} \mathrm{C}$

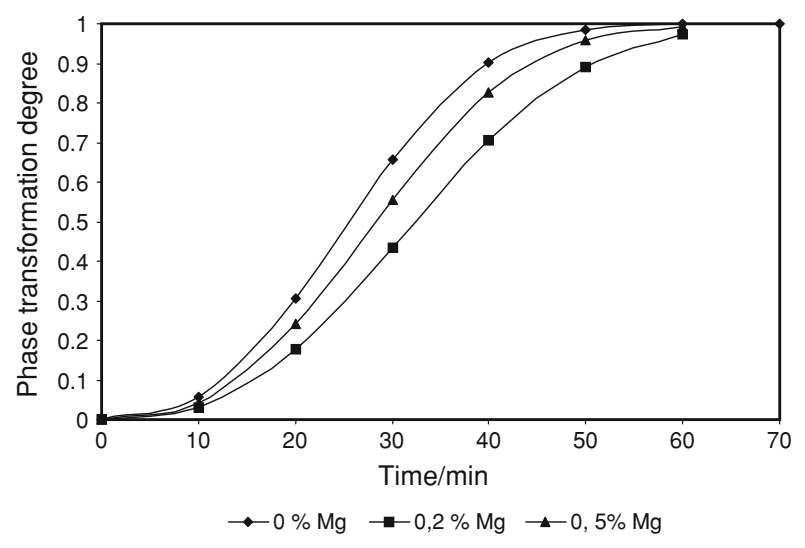

Fig. 8 Influence due to the addition of $\mathrm{MgO}$ on the $\mathrm{TiO}_{2}$ transformation degree at temperature of $800{ }^{\circ} \mathrm{C}$

Little influence due to the addition of $\mathrm{Mg}$ on transition degree at the beginning of transformation at $850{ }^{\circ} \mathrm{C}$ is observed as presented in Fig. 8 .
Table 1 Values of $\mathrm{TiO}_{2}$ transformation rate constant $k\left(\mathrm{~min}^{-1}\right)$

\begin{tabular}{lll}
\hline Addition & $k$ & \\
\cline { 2 - 3 } & $800{ }^{\circ} \mathrm{C}$ & $850{ }^{\circ} \mathrm{C}$ \\
\hline 0 & 0.0342 & 0.071 \\
$0.2 \% \mathrm{Al}$ & 0.0236 & 0.0501 \\
$0.5 \% \mathrm{Al}$ & 0.0187 & 0.0375 \\
$0.2 \% \mathrm{Mg}$ & 0.0272 & 0.0855 \\
$0.5 \% \mathrm{Mg}$ & 0.0308 & 0.1028 \\
\hline
\end{tabular}

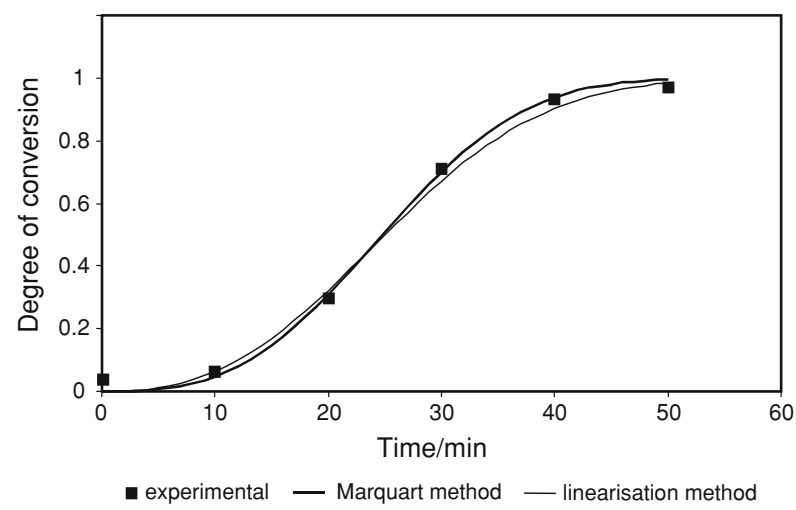

Fig. 9 Comparison of results of linearisation and Marquart method calculations for the anatase-rutile transformation without additions at temperature $800{ }^{\circ} \mathrm{C}$

Table 1 shows the values of the phase transformation rate constant for these experiments, calculated using the same $A 8 / 3$ model and in the same manner as that used for samples without additions.

Table 1 shows that the influence of aluminium presence in calcination process is essential for the rate of anataserutile transformation. The ratios of rate constants without additions to those with additions of 0.2 and $0.5 \% \mathrm{Al}$ are equal to 1.45 and 1.83 (at $800{ }^{\circ} \mathrm{C}$ ) and 1.42 and 1.89 (at $850{ }^{\circ} \mathrm{C}$ ), respectively. At both temperatures, the increase of the aluminium concentration is shown to have a significant inhibitory influence of aluminium on the phase transformation. Additions of $\mathrm{Mg}$ on transition rate are shown to have very little influence.

The method of investigations applied for isothermal calcination of titanium dioxide suspension with additions of magnesium and aluminium ions enables us to identify the effects of the different substances on the phase transformations kinetics, and allows setting the range of transformation temperatures, the temperature of the maximum transition rate and the calculation of kinetic parameters which can be extremely useful in the development and implementation of industrial processes. 
The calculations of kinetic parameters in the AvramiErofeev equation were realized by a linearisation method and the Marquart method [26]. In these calculations, the Avrami-Erofeev equation was used in the following formula:

$\alpha=1-\exp \left(-k \tau^{\mathrm{n}}\right)$

in the case of the Marquart method, and in the formula:

$\ln [-\ln (1-\alpha)]=\ln k+n \ln \tau$

in the case of calculations by the linearisation method.

Results of calculations for the kinetics of the phase transformation in temperature $800{ }^{\circ} \mathrm{C}$ are presented in Fig. 9. The degree of curves fitting which was obtained by the Marquart method was equal $R^{2}=0.999$; however, in the case of the method of the linearisation $R^{2}=0.993$.

Differences in the calculated values of parameters obtained with different methods result from the so-called mistakes of transformations, which are related to the number of decimal places in the given value. It follows that the obtained results from calculations must be verified.

\section{Conclusions}

The findings of the study led us to the conclusions as follows:

Transition profiles of $\mathrm{TiO}_{2}$ transformation at different experimental temperatures are sigmoidal.

The kinetics of $\mathrm{TiO}_{2}$ anatase-rutile transformation can be described by Avrami-Erofeev model with $n=8 / 3$.

The additions of $\mathrm{Al}$ and $\mathrm{Mg}$ salts to $\mathrm{TiO}_{2}$ suspension on the thermal dehydroxilation and desulphuration have minimal effects.

The phase transformation of titanium dioxide from anatase to rutile with temperatures ranging from 800 to $900{ }^{\circ} \mathrm{C}$ is complete after $40-60$-min processing time. The maximum rate of anatase-rutile transformation is observed when the transformation degree equals 0.4647 . The kinetic triplet values of anatase-rutile transformation were $n=$ $8 / 3, E=178 \mathrm{~kJ} \mathrm{~mol}^{-1}$, and $A=1.475 \times 10^{7} \mathrm{~min}^{-1}$.

When $\mathrm{Al}$ salts are added to titanium dioxide suspension, the transformation of anatase into rutile occurs over a much longer time, and this influence grows together with the increasing concentration of the addition. The presence of $0.2-0.5 \% \mathrm{Al}$ in $\mathrm{TiO}_{2}$ lowers the value of rate constant of transformation $k$ by $1.4-1.8$ time. The influence due to the addition of $\mathrm{Mg}$ on the kinetics of the phase transformation is rather negligible.

Open Access This article is distributed under the terms of the Creative Commons Attribution License which permits any use, distribution, and reproduction in any medium, provided the original author(s) and the source are credited.

\section{References}

1. Gennari FG, Pasquevich DM. Kinetics of the anatase-rutile transformation in $\mathrm{TiO}_{2}$ in the presence of $\mathrm{Fe}_{2} \mathrm{O}_{3}$. J Mater Sci. 1998;33:1571-8.

2. Riyas S, Ahmed Yasir V, Mohan Das PN. Crystal structure transformation of $\mathrm{TiO}_{2}$ in presence of $\mathrm{Fe}_{2} \mathrm{O}_{3}$ and $\mathrm{NiO}$ in air atmosphere. Bull Mater Sci. 2002;25(4):267-73.

3. Xiaohui Yu, Hou T, Sun X, Li Y. The influence of defects on Modoped $\mathrm{TiO}_{2}$ by first-principles studies. ChemPhysChem. 2012; 13(6):1514-21.

4. Hirano $\mathrm{M}$, Ota $\mathrm{K}$, Ito $\mathrm{T}$. Anatase-type $\mathrm{TiO}_{2}$ and $\mathrm{ZrO}_{2}$-doped $\mathrm{TiO}_{2}$ directly formed from titanium(III) sulfate solution by thermal hydrolysis: effect of the presence of ammonium peroxodisulfate on their formation and properties. J Am Ceram Soc. 2005; 88(12):3303-10.

5. Okada K, Yamamoto N, Kameshima Y, Yasumori A, Mackenzie KJD. Effect of silica additive on the anatase-to-rutile phase transformation. J Am Ceram Soc. 2001;84(7):1591-6.

6. Barakat MA, Hayes G, Shah SI. Effect of cobalt doping on the phase transformation of $\mathrm{TiO}_{2}$ nanoparticles. J Nanosci Nanotechnol. 2005; Vol.X:1-7.

7. Vayssieres L, Österlund L. Chapter 8. Fourier-transform infrared and Raman spectroscopy of pure and doped $\mathrm{TiO}_{2}$ photocatalysts. On solar hydrogen and nanotechnology. Hoboken: Wiley; 2010.

8. Wang Z, Deng X. $\mathrm{Al}_{2} \mathrm{O}_{3}$ composite agent effects on phase transformation of nanometer $\mathrm{TiO} 2$ powder. Mater Sci Eng B. 2007;140:109-13.

9. Topuz BB, Gündüz G, Mavis B, Çolak Ü. The effect of tin dioxide $(\mathrm{SnO} 2)$ on the anatase-rutile phase transformation of titania $(\mathrm{TiO} 2)$ in mica-titania pigments and their use in paint. Dye Pigments. 2011;90:123-8.

10. Przepiera A, Jabłoński M, Wiśniewski M. Calculation of kinetic parameters from TG curve on the base of dehydration process of hydrous titanium dioxide. J Therm Anal. 1990;36:2135.

11. Przepiera A, Jabłoński M, Wiśniewski M, Dąbrowski W. Phase changes of hydrous titanium oxides in temperature range 298-1198 K. Mater Sci Forum. 1993;133-136:651.

12. Zhou W, Gai L, Hu P, Cui J, Liu X, Wang D, Li G, Jiang H, Liu D, Liu $\mathrm{H}$, Wang J. Phase transformation of $\mathrm{TiO}_{2}$ nanobelts and $\mathrm{TiO} 2(\mathrm{~B}) /$ anatase interface heterostructure nanobelts with enhanced photocatalytic activity. Cryst Eng Comm. 2011;22:6643-9.

13. Lin H, Li L, Zhao M, Huang X, Chen X, Richeng Y. Synthesis of high-quality brookite $\mathrm{TiO}_{2}$ single-crystalline nano-sheets with specific facets exposed: tuning catalysts from inert to highly reactive. J Am Chem Soc. 2012;134(20):8328-31.

14. Jamieson JC, Olinger B. Pressure-temperature studies of anatase, brookite, rutile, and $\mathrm{TiO}_{2}$ (II); a discussion. Am Miner. 1969; 54:1477-81.

15. Withers AC, Essene EJ, Zhang Y. Rutile/TiO ${ }_{2} \mathrm{II}$ phase equilibria. Contrib miner Petrol. 2003;145:199-204.

16. Kavei G, Nakaruk A, Sorrell CC. Equilibrium state of anatase to rutile transformation for titanium dioxide film prepared by ultrasonic spray pyrolysis technique. Mater Sci Appl. 2011;2: $700-5$.

17. Zhang H, Banfield FJ. Understanding polymorphic phase transformation behaviour during growth of nanocrystalline aggregates: insights from $\mathrm{TiO}_{2}$. J Phys Chem. 2000;104:3481-7.

18. Zhang J, Li M, Feng Z, Chen J, Li C. UV Raman spectroscopic study on $\mathrm{TiO}_{2}$. I. Phase transformation at the surface and in the bulk. J Phys Chem B. 2006;110:927-35.

19. Shannon RD, Pask JA. Kinetics of the anatase-rutile transformation. J Am Ceram Soc. 1965;48(8):391-8.

20. Gouma PJ, Mills MJ. Anatase-to-rutile transformation in titania powders. J Am Ceram Soc. 2001;84(3):619-22. 
21. Barin I, Knacke O. Thermochemical properties of inorganic substances. Berlin: Springer; 1973.

22. Krishna Rao KV, Nagender Naidu SV. Leela Iyengar, Thermal expansion of rutile and anatase. J Am Ceram Soc. 1970;53(3):124-6.

23. Vyazovkin S, Burnham AK, Criado JM, Perez-Maqueda LA, Popescu C, Sbirrazzuoli N. ICTAC Kinetics Committee recommendations for performing kinetic computations on thermal analysis data. Thermochim Acta. 2011;520:1-19.

24. Kang-Zhen X, Zuo X-G, Zhang H, Yan B, Huang J, Hai-Xia M, Wang B-Z, Zhao F-Q. Synthesis and thermal behavior of a new high-energy organic potassium salt K(AHDNE). J Therm Anal Calorim. 2012;110(2):585-91.
25. Emen FM, Ocakoglu K, Kulcu N. An investigation of decomposition stages of a ruthenium polypyridyl complex by non-isothermal methods. J Therm Anal Calorim. 2012;110(2):799-805.

26. Press WH, Flannery BP, Teukolsky AA, Vetterling WT. Numerical recipes, the art of scientific computing. Cambridge: Cambridge University Press; 1986. 